\title{
Tissue hypoxia and metabolic acidosis—significant factors?
}

\author{
J. S. S. STEWART \\ Royal Albert Edward Infirmary, Wigan
}

\begin{abstract}
Summary
In very rare cases severe metabolic acidosis may cause hypotension, respiratory depression and cardiac arrest. Although rare this cause of shock is important because correction of the metabolic acidosis may be life-saving.

Mild metabolic acidosis is relatively common in cases of hypoxia and shock, and is an index of the severity of these. Recurrent metabolic acidosis, which reflects failure of the therapy to control the cause of the acidosis, is a gloomy prognostic sign.
\end{abstract}

\section{Introduction}

The relevance of metabolic acidosis to shock has only recently been defined and, like the situation with respect to acidosis and cardiac arrest (Stewart, 1967), confusion in the past has been due to the fact that shock may be the cause or the result of metabolic acidosis.

\section{Shock as cause of acidosis}

There is much experimental work which testifies that shock causes metabolic acidosis and some clinical examples of this are included in the present paper. The metabolic acidosis which results is mild and there is no evidence that this mild metabolic acidosis causes harm. It is important, however, as a prognostic index about the efficacy of treatment of shock.

\section{Acidosis as cause of shock}

Acidosis is a relatively rare cause of shock (Stewart, 1965) and examples include acid load during massive blood transfusion or embolectomy and generalized hypoxia due to hypoventilation or lung shunting. Many of these cases occur during general anaesthesia and, although they are rare, such cases are important because correction of the metabolic acidosis with sodium bicarbonate solution may be life saving. An example of the shock/acidosis syndrome is given in the following case history. The patient was treated at Addenbrooke's Hospital, Cambridge, in December 1966 and I am indebted to Mr B. M. Truscott for permission to include details of this patient admitted under his care.
Case 1

This patient, a female aged 67 years, was admitted $\vec{\omega}$ with a 48-hr history of colicky abdominal pain, with severe upper abdominal pain and vomiting of $6 \mathrm{hr} C$ duration. There was a past history of hiatus hernia 3 . with haematemesis from an oesophageal ulcer 8 c years previously and a history of hypertension with of a previous blood pressure recorded at $200 / 120 \mathrm{mmHg}$. \%

On examination the patient was pale and shocked, $\stackrel{\sigma}{\infty}$ with blood pressure 100/? $\mathrm{mmHg}$. The abdomen $\infty$ was soft with no tenderness and no guarding but $\stackrel{\circ}{5}$ was silent with shifting dullness present. There was $\overrightarrow{-}$ some dullness at the right base and gastric aspirations gave a positive test for blood. The chest film was unsatisfactory due to artefact but a plain X-ray $\stackrel{\infty}{\rightarrow}$ of abdomen showed some gas under the diaphrage $\vec{\circ}$ and an electrocardiogram showed no evidence of infarct. She was treated initially with intravenousi normal saline $(250 \mathrm{ml})$ followed by plasma (2 litres) given rapidly. An arterial blood sample was obtained for $\mathrm{pH}$ measurement but before the result of this was known the patient showed progressive hypo- $\frac{\circ}{\Phi}$ tension and respiratory depression. She improved $\cong$ somewhat with $80 \mathrm{mEq}$ of intravenous sodium $\bar{O}$ bicarbonate solution, and a further arterial blood 3 sample was obtained. The patient's condition had not at any time improved sufficiently for laparotomy to be contemplated and shortly afterwards her condition further deteriorated with absent peripheral pulses and cessation of respiration. Resuscitation was not attempted. It was subsequently known that the first arterial blood sample had a pH of 7.07 and the second, after $80 \mathrm{mEq}$ of sodium bicarbonate, had a $\mathrm{pH}$ of $7 \cdot 17$. At post mortem a large perforated peptic ulcer was found.

In retrospect it would appear that shock had caused metabolic acidosis which in this instance was $N$ progressive and severe. This severe metabolic acidosis caused both hypotension and respiratory de- 0 pression and, in the absence of adequate correction, $\stackrel{\omega}{ }$ the patient continued on the downward spiral to death.

\section{Review of intensive care cases}

All cases admitted to the Intensive Care Unit at the Royal Albert Edward Infirmary, Wigan, under $\underset{\mathbb{D}}{\stackrel{D}{D}}$ 
the author's care in the year from November 1967 to October 1968 are reviewed (Table 1). The series is

TABLE 1. General surgical cases in Intensive Care Unit

\begin{tabular}{lccc}
\hline & Shock & Other & Totals \\
\hline Observation & 8 & 7 & 15 \\
Therapy & & & \\
$\quad$ Surviving & 4 & 2 & 6 \\
$\quad$ Fatal & 5 & 1 & 6 \\
Totals & 17 & 10 & 27 \\
\hline
\end{tabular}

obviously selected. It does not include patients who collapsed suddenly in the general ward and who died quickly, although some of these were due to septic shock. Nor does it include patients who were admitted in shock and treated successfully in the Casualty Department. The series is, however, of value in that the cases were carefully documented and therefore provide a basis for discussion. Some cases were admitted for observation and others were admitted for therapy.

\section{Observation cases}

Most of the observation cases were in the Intensive Care Unit for less than $48 \mathrm{hr}$ and in eight of fifteen they were observed principally because there was a risk of shock. The routine care of these cases includes the time-honoured nursing observations, and record of pulse rate, temperature and respiration, together with observation of the patient's colour, state of the peripheral circulation and blood pressure. In addition there is a careful fluid balance with regular biochemical estimations of blood electrolytes, blood urea and haematocrit. Acid-base studies were obtained in only a few instances but in all of these few they were normal.

\section{Therapy cases}

The cases admitted for therapy included those with established shock. In such cases additional observations are made. The urine flow from an indwelling catheter is measured hourly and an output of $40 \mathrm{ml} / \mathrm{hr}$ is considered adequate. The venous pressure is measured, usually by clinical observation of the neck veins but in some cases by insertion of a venous catheter connected to a manometer. The lungs are frequently observed by auscultation and at least daily by chest X-ray. Blood gases including hydrogen ion concentration $(\mathrm{pH})$, partial pressure of carbon dioxide $\left(\mathrm{PCO}_{2}\right)$, base excess (BE) and standard bicarbonate (SB) are frequently estimated. It is desirable also to measure the partial pressure of oxygen $\left(\mathrm{Po}_{2}\right)$. In therapy, oxygen, volume replacement and adrenaline are of prime importance and the effect of these, particularly on the arterial pressure, is carefully observed.

TABLE 2. Intensive Care Unit: blood gases in surviving cases

\begin{tabular}{|c|c|c|c|c|c|c|}
\hline No., sex, age, diagnosis & pH & $\begin{array}{l}\mathrm{PCO}_{2} \\
(\mathrm{~mm})\end{array}$ & $\begin{array}{l}\text { Base } \\
\text { excess } \\
(\mathrm{mm} / \mathrm{l})\end{array}$ & $\begin{array}{c}\text { Standard } \\
\text { bicarbonate } \\
(\mathrm{mEq} / \mathrm{l})\end{array}$ & $\begin{array}{c}\text { Days } \\
\text { post- } \\
\text { operation }\end{array}$ & $\begin{array}{c}\text { Bicarbonate } \\
\text { therapy }\end{array}$ \\
\hline $2, \mathrm{M}, 48$, pneumothorax & $\begin{array}{l}7 \cdot 28 \\
7 \cdot 36\end{array}$ & $\begin{array}{l}45 \\
43\end{array}$ & $\begin{array}{l}-7 \\
-1 \cdot 5\end{array}$ & $\begin{array}{l}19 \\
22 \cdot 5\end{array}$ & $\begin{array}{l}0 \\
1\end{array}$ & $\bar{t}$ \\
\hline $3, \mathbf{M}, 13$, pneumothorax & $\begin{array}{l}7 \cdot 26 \\
7 \cdot 39\end{array}$ & $\begin{array}{l}70 \\
42\end{array}$ & $\begin{array}{l}-4.5 \\
+0.5\end{array}$ & $\begin{array}{l}21 \\
24 \cdot 5\end{array}$ & $\begin{array}{l}0 \\
1\end{array}$ & $\overline{+}$ \\
\hline $4, M, 62$, aneurysm, cardiac arrest & $\begin{array}{l}7 \cdot 36 \\
7 \cdot 44 \\
7 \cdot 40\end{array}$ & $\begin{array}{l}85 \\
48 \\
39\end{array}$ & $\begin{array}{c}+15 \\
+6.5 \\
0\end{array}$ & $\begin{array}{l}37 \cdot 5 \\
29 \\
23 \cdot 7\end{array}$ & $\begin{array}{r}0 \\
5 \\
10\end{array}$ & $\begin{array}{l}+ \\
+ \\
+\end{array}$ \\
\hline
\end{tabular}

TABLE 3. Intensive Care Unit: blood gases in fatal cases

\begin{tabular}{|c|c|c|c|c|c|c|}
\hline No., sex, age, diagnosis & pH & $\begin{array}{l}\mathrm{PcO}_{2} \\
(\mathrm{~mm})\end{array}$ & $\begin{array}{l}\text { Base } \\
\text { excess } \\
(\mathrm{mm} / \mathrm{l})\end{array}$ & $\begin{array}{c}\text { Standard } \\
\text { bicarbonate } \\
\text { (mEq/l) }\end{array}$ & $\begin{array}{c}\text { Days } \\
\text { post- } \\
\text { operation }\end{array}$ & $\begin{array}{c}\text { Bicarbonate } \\
\text { therapy }\end{array}$ \\
\hline $5, \mathrm{~F}, 77$, peritonitis & $\begin{array}{l}6 \cdot 80 \\
7 \cdot 21 \\
7 \cdot 46\end{array}$ & $\begin{array}{l}44 \\
16 \cdot 5 \\
39\end{array}$ & $\begin{array}{l}-27 \\
-20 \\
+4\end{array}$ & $\begin{array}{l}6 \\
9 \cdot 5 \\
27\end{array}$ & $\begin{array}{l}0 \\
0 \\
1\end{array}$ & $\begin{array}{l}- \\
+ \\
+\end{array}$ \\
\hline $6, F, 86$, peritonitis & $\begin{array}{l}7 \cdot 33 \\
7 \cdot 39\end{array}$ & $\begin{array}{l}28 \cdot 5 \\
42\end{array}$ & $\begin{array}{r}-9 \\
0\end{array}$ & $\begin{array}{l}17 \cdot 2 \\
24\end{array}$ & $\begin{array}{l}0 \\
5\end{array}$ & $\overline{+}$ \\
\hline $7, F, 87$, peritonitis, cardiac arrest & $\begin{array}{l}7 \cdot 55 \\
7 \cdot 37\end{array}$ & $\begin{array}{l}34 \\
48\end{array}$ & $\begin{array}{l}+6 \\
+1\end{array}$ & $\begin{array}{l}29 \\
24 \cdot 5\end{array}$ & $\begin{array}{l}0 \\
2\end{array}$ & $\begin{array}{l}+ \\
+\end{array}$ \\
\hline $8, \mathbf{M}, 78$, pyonephrosis, pneumonia & $7 \cdot 32$ & $21 \cdot 5$ & -13 & $14 \cdot 6$ & - & - \\
\hline $9, F, 50$, fistula & $\begin{array}{l}7 \cdot 34 \\
7 \cdot 18\end{array}$ & $\begin{array}{r}45 \\
105\end{array}$ & $\begin{array}{l}+3 \cdot 5 \\
+3\end{array}$ & $\begin{array}{l}21 \cdot 5 \\
26 \cdot 5\end{array}$ & $\begin{array}{l}20 \\
21\end{array}$ & $\bar{t}$ \\
\hline
\end{tabular}


Twelve cases were admitted for therapy. Shock was present in four of the six survivors and in five of the six deaths. Acid-base studies were obtained in three surviving cases (Table 2) and in five fatal cases (Table 3).

\section{Clinical details}

\section{Case 2}

This patient became cyanosed and hypotensive just after induction of anaesthesia, and remained so during pyloroplasty and vagotomy. At the conclusion of the operation acid-base studies showed moderate mixed acidosis, predominantly metabolic. The patient had apparently developed a pneumothorax during induction and this was treated by insertion of a pleural drain. The acid-base state was normal the next day.

\section{Case 3}

This patient fell from a tree and sustained multiple injuries including splenic rupture, fractured ribs with pneumothorax and head injury with inhalation of blood. After splenectomy, bronchial aspiration and pleural drainage there was a mixed acidosis, predominantly respiratory. The acid-base state was normal next day.

\section{Case 4}

This patient was admitted with a leaking abdominal aortic aneurysm. During resection and grafting the patient sustained a cardiac arrest which was treated by external cardiac massage and an empirical dose of sodium bicarbonate solution. At the end of the operation he had a metabolic alkalosis, due to an overdose of bicarbonate, and a respiratory acidosis with a normal $\mathrm{pH}$. There was a poor respiratory reserve which necessitated tracheostomy and a normal acid-base state was not restored until the 10th post-operative day.

\section{Case 5}

This patient was admitted with an appendix abscess which was initially treated conservatively but laparotomy was performed when the patient collapsed suddenly with generalized peritonitis. A large retroperitoneal abscess was found and hemicolectomy was performed. At the conclusion of the operation the patient was hypotensive with hyperpnoea and an empirical dose of sodium bicarbonate was given. Further bicarbonate was given when the acidbase results (before and after this empirical treatment) were known. The next day, when the acidbase state was nearly normal, the patient collapsed suddenly in cardiac arrest and was resuscitated. She developed a further cardiac arrest, resuscitation wasz not attempted and at post mortem a phaeochromo- $\frac{\mathbb{Q}}{\Omega}$ cytoma, which may have contributed to the cardiac. arrest, was found.

\section{Case 6}

This patient had a transverse colostomy for per $\frac{\bar{y}}{\bar{n}}$. forated diverticulitis. At the conclusion of the opera- $\bar{\Phi}$ tion a metabolic acidosis was masked by compensatory respiratory alkalosis and was treated with ${ }^{\circ}$ bicarbonate. During the next 5 days metabolic acid- $\overrightarrow{0}$ osis required correction and the patient died on the 7 th post-operative day.

\section{Case 7}

This patient was admitted with a perforated duo- $\frac{\vec{c}}{\mathrm{C}}$ denal ulcer and collapsed in cardiac arrest. She wasir resuscitated with external cardiac massage and empirical sodium bicarbonate therapy was given but'r she remained decerebrate. She was treated conserva- $\vec{\infty}$ tively but developed respiratory complications as은 indicated by the respiratory acidosis on the 2 nd dayand died.

\section{Case 8}

This patient was admitted with acute retention off $\vec{\circ}$ urine with uraemia, pyuria and pneumonia. A collapsed in septic shock and a moderate metabofico acidosis was nearly fully compensated by respiratory? alkalosis. He died quickly in spite of empirical antibiotics and other therapy.

\section{Case 9}

This patient developed a fistula following a total gastrectomy for gastric carcinoma. Following? closure of the fistula, respiratory complications de-0 veloped and in spite of bronchoscopy, antibiotics and other therapy the patient developed increasing? respiratory acidosis and died.

TABLE 4. Causes of surgical shock

\begin{tabular}{l} 
Oligaemia \\
Haemorrhage, plasma loss, dehydration \\
Sepsis \\
Peritonitis, enterocolitis, septicaemia \\
Vascular catastrophe \\
Myocardial infarction, pulmonary embolism \\
Ruptured aneurysm \\
Iatrogenic causes \\
Vasodilators, narcotics \\
Neurogenic disturbance \\
Vasovagal, pain \\
Biochemical upset \\
Acidosis, cortisone lack, noradrenaline withdrawal \\
Pulmonary causes \\
Inhalation of vomitus, massive collapse \\
\hline
\end{tabular}




\section{Discussion}

Acidosis was mild to moderate, more than $7 \cdot 0$, in all but one case. It was associated with hypoxia or shock in all the present cases and was an index of the severity of these. Metabolic acidosis was easily corrected but correction of respiratory acidosis was more difficult. Where the cause of the respiratory acidosis could be treated, as in cases of pneumothorax, the prognosis was good, but in the patients with post-operative respiratory complications the prognosis was bad. Recurrent metabolic acidosis, prominent in peritonitis, reflected a failure to control shock and correction of the metabolic acidosis alone was of little value. Thus mild metabolic acidosis, particularly recurrent metabolic acidosis, is a gloomy prognostic sign.

Although it is the main purpose of this paper to discuss the association of metabolic acidosis with shock it should be remembered that metabolic acidosis has but a small place in the aetiology of shock (Table 4).

\section{References}

STEWART, J.S.S. (1965) The management of surgical shock: two important syndromes, J. roy. Coll. Surg. Edinb. 10, 228.

STEWART, J.S.S. (1967) Extreme acidosis in man. Ann. Anesth. Franc. 8, 127. 